\title{
La deuda: Albers, Acosta, Augusto de Campos
}

2. Raúl ANTElo / Universidade Federal de Santa Catarina / antelo@floripa.com.br

\section{Resumen}

Una imagen es un texto. Un texto es imagen. Ambos son archivos en que las relaciones sociales entre individuos son mediadas por las imágenes. Son una exigencia a la cual es imposible no responder. Cada imagen sigue la huella abierta por su mismo movimiento y puede entrar en constelación con otras imágenes.

\section{Abstract}

An image is a text. A text is an image. And both are archives where social relations between people are mediated by images. They are an exigence to which one cannot but respond. Every image follows the path of its movement and may enter into constellation with other images.

Key words: text $\cdot$ image $\cdot$ exigence

Palabras clave: texto $\cdot$ imagen $\cdot$ exigencia

La artista alemana Anni Albers tuvo su primer contacto con el arte azteca, todavía

Fecha de recepción: $30 / 6 / 2017$ Fecha de aceptación: $25 / 8 / 2017$ do, Josef Albers, y un matrimonio amigo, Theodore y Barbara Dreier, fundadores del experimental Black Mountain College, donde los Albers enseñarían entre I933 y 1949, y al cual llegaron por la mediación del arquitecto Phillip Johnson (Theodore era sobrino de Katherine Dreier, fundadora con Duchamp y Man Ray de la Société Anonyme, el primer museo de arte contemporáneo neoyorkino). Es entonces cuando Anni y Josef Albers se deparan con una dimensión de lo artístico que los acompañaría por toda la vida (Albers 2006).

En efecto, la cuestión del diseño arcaico era algo sobre lo cual su compatriota, Roberto Lehmann-Nitsche, ya había reparado, sea en las conferencias de extensión universitaria sobre dibujos primitivos, que dicta en La Plata entre 1907 y 1909, y que lo llevarían a replicar en el museo de esa ciudad el portal erigido al sol en Tiahuanaco, o bien en las imágenes del Coricancha que él mismo analiza (I928). José Sabogal recorre la región cuzqueña en I9I8 pero, a esas alturas, 
Ricardo Rojas ya había asimismo llamado la atención sobre los diseños indígenas (I9I5), ${ }^{1}$ secundado, inmediatamente, por Clemente Onelli (I9I6). Por otra parte, Adolfo Best Maugard también había divulgado en México un manual metódico de dibujo para las escuelas, que incluía una colaboración del poeta José Juan Tablada sobre la función social del arte (1923). Ese mismo año, 1923, Gonzalo Leguizamón Pondal y Alberto Gelly Cantilo editarían en Buenos Aires un libro congénere, Viracocha (I923). Si a esto le sumamos la prédica del arquitecto Martín Noel y los trabajos de su discípulo, Ángel Guido, constatamos que la idea de Eurindia, planteada por Ricardo Rojas en 1924, contaba ya con muchos adeptos (Guido I930, 1940), en toda la región. En 1927, Ángel Guido comienza a trabajar sobre las «tragedias incaicas inéditas» (1927) de Rojas y auspiciado por la Universidad de Southern California, pasa una temporada, entre septiembre y diciembre de 1933, en México, estudiando la influencia indígena en la arquitectura y decoración de los siglos XVII y XVIII. ${ }^{2}$ Otro alemán, el musicólogo Curt Lange, radicado en Uruguay, también recorre por ese entonces los Andes (I938), al tiempo en que Torres García, retornado a Montevideo, ensaya una confluencia de lo telúrico con el ideario "círculo y cuadrado», que reivindica la fragmentación preincaica en detrimento de la imagen normalizada inca (1939, 1965), programa del cual se nutren más tarde artistas como Libero Badii, con su concepto de arte siniestro. Mientras tanto, Siqueiros, tras su experiencia en el Plata, acude a la invitación paulista de Flávio de Carvalho y Oswald de Andrade, abortada por la policía. Es la época, además, en que una artista austríaca, Gertrudis Chale, contemporánea de los Albers, recorre el altiplano pero, a diferencia de los artistas alemanes, no se interesa por el motivo geométrico sino por los grandes espacios, la pampa y la puna, donde encuentra la materialización de paisajes imaginarios, los mismos que ya conocía a partir de la obra de un surrealista acefálico como Yves Tanguy (1989, 1996, 200I).

\section{$* * *$}

Pero los frecuentes viajes de los Albers a México (se cuentan I4 en total) los llevarían a explorar, no tanto la materialidad remanente de una cultura, como harían sus colegas latinoamericanos, sino, a partir de la abstracción geométrica, la inmaterialidad del color y su potencialidad en abierto. Con un grabado de esos participa Josef Albers del salón de mayo (San Pablo, I939), curado por Flávio de Carvalho y, asimismo, las grecas que encuentra repetidas a la saciedad en el Palacio de las Columnas de Mitla, en Oaxaca,

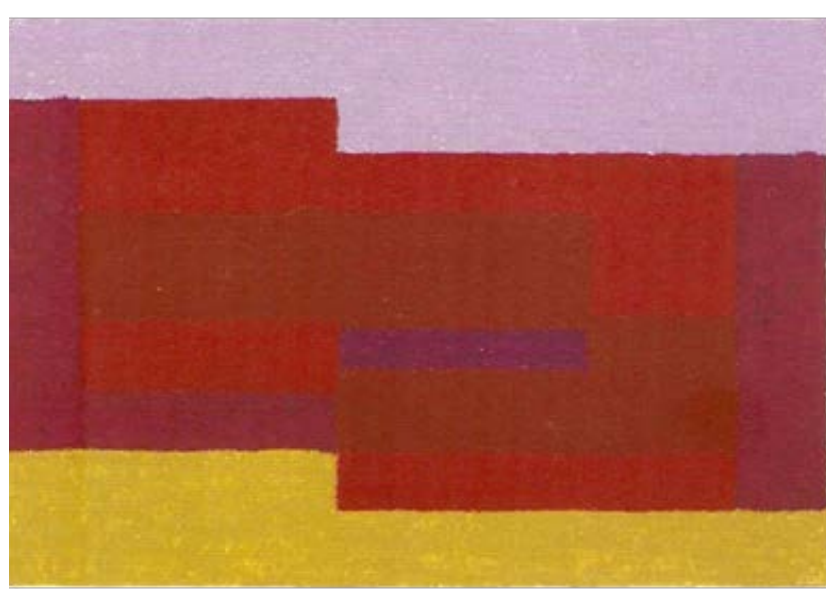

Fig. I Josef Albers - Mitla - 1940 - The Josef and Anni Albers Foundation le inspiran al mismo artista el franco colorido de un óleo como "A Mitla» (I940) (Fig. I), que recuerda los muros pintados de rojo intenso rodeando el Palacio de las Columnas. 
En esa tela, que prefigura la serie de Variantes, también conocida como Adobes, iniciada a finales de 1946, constatamos lo acertado de las observaciones previas de Lehmann-Nitsche (I927:I45-I59). Ese mismo monumento le provocaría a Alejo Carpentier, casi simultáneamente, una conjunción entre lo real-maravilloso y lo barroco.

El templo de Mitla se encuentra cerca de Oaxaca y nos presenta una fachada maravillosamente equilibrada en sus volúmenes, una serie de cajones del mismo tamaño, en cada uno se desarrolla una composición abstracta distinta a la anterior; es decir, no se trabaja ya por simetría; cada uno de esos cajones es célula proliferante de una composición barroca que se inserta en un conjunto en general barroco.

Yo no puedo menos, cuando contemplo la fachada del templo de Mitla, que evocar las treinta y tres variaciones de un tema de Diabelli, de Beethoven, donde nos entrega a partir de un tema inicial inocuo, treinta y tres variaciones monumentales, que como decía recientemente un crítico de la nueva hornada, más que variaciones musicales, son treinta y tres objetos sonoros. Los cajones de Mitla son dieciocho objetos plásticos. Del mismo modo pienso también, cuando veo esas composiciones del templo de Mitla, en las variaciones para orquesta de Arnold Schömberg (Carpentier 1984:II7). (Figs. 2 y 3).

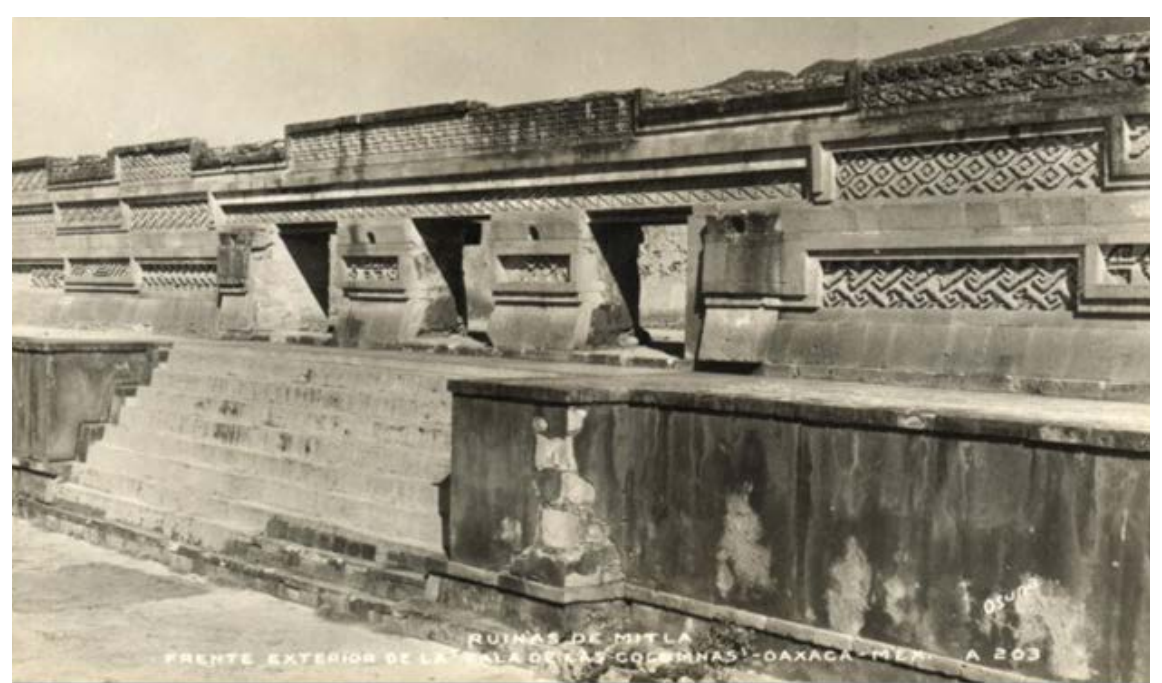

Fig. 2 Templo de Mitla - copy

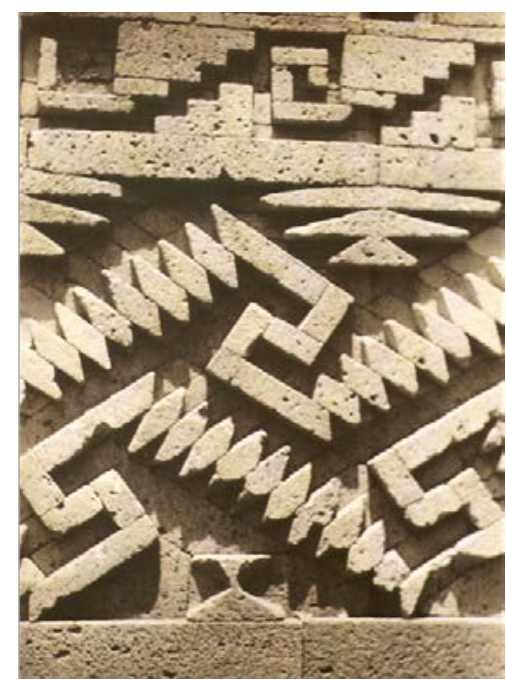

Fig. 3 Josef Albers - Detalle de una construcción de piedra - Mitla - sf copy.

Es verdad que en su célebre ensayo "De lo real maravilloso latinoamericano» (1949), Carpentier habla de «la belleza abstracta — absolutamente abstracta — del Templo de Mitla, con sus variaciones sobre temas plásticos ajenos a todo empeño figurativo» (1976:117). Pero su reivindicación de Mitla se inclina hacia la constancia ecuménica de la forma en detrimento de la alteración singular de fuerzas enfrentadas; por ello, a diferencia de Carpentier y su rescate de la variación barroca, diríamos que Josef Albers, más que profundizar una búsqueda identitaria, veía en la intensidad del color de Mitla una materialización del abandono, preocupación 
compartida con sus colegas de la Bauhaus, no solo por Walter Gropius, sino también por los pintores Paul Klee y Lyonel Feininger, pero fundamentalmente por Wassily Kandinsky, a quien lo unía una profunda hermandad, porque lo que más le interesaba a Albers era ver cómo se modificaban los colores unos a otros, según las diversas proporciones y cantidades, hasta perder su identidad y tornarse irreconocibles. En una carta a Kandinsky de 1936, precisamente, Albers declara extasiado que México es la tierra prometida del arte abstracto, donde el arte folk aún está vivo, algo con lo cual Walter Benjamin difícilmente concordaría, ya que por la misma época llegó a escribir que el arte folk era una variante del kitsch (278-279).

\section{$* * *$}

Si se comparan las fotos que, frecuentemente, Juan Rulfo y Josef Albers obtuvieron de esos mismos monumentos, por ejemplo, la pirámide de Tenayuca, es posible observar que Rulfo, más cercano a la estructura prehispánica, crea una imagen abstracta de ella (Fig. 4), mientras que Albers, en cambio, es más analítico, desconstruye la forma y opta por mostrar todos los elementos que forman su estructura (Fig. 5 y 6). Rulfo de algún modo estetiza la pirámide, mientras que Albers, alejado de la estructura visible, prefiere verla completa sólo recién a través de otras imágenes, gracias a los posteriores montajes, que le sirven para abstraer esquemas y traducirlos en pinturas.

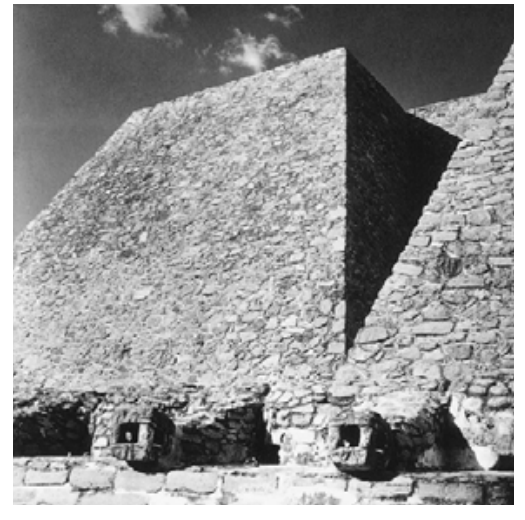

Fig. 4 Juan Rulfo - Pirámide de Tenayuca - México sf

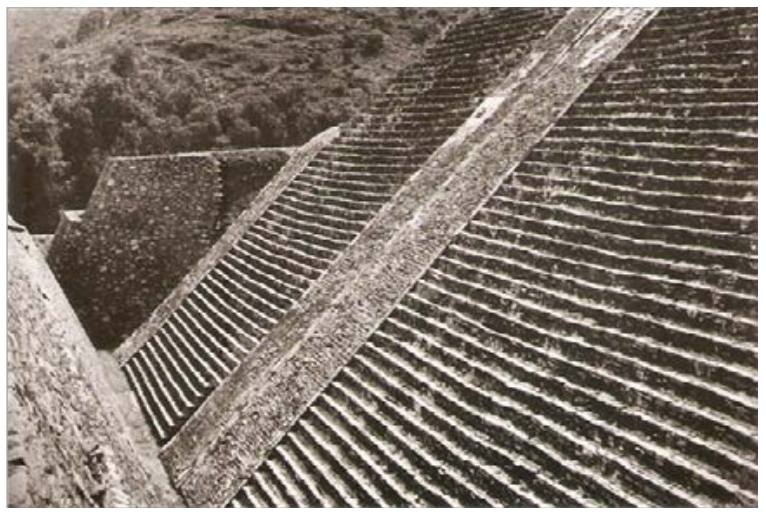

Fig. 5 Josef Albers - Sin título - Tenayuca - México

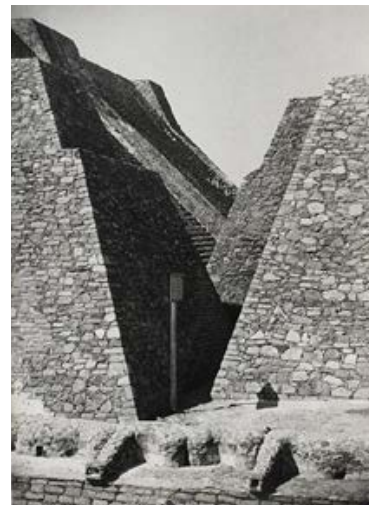

Fig. 6 Josef Albers - Sin título - Tenayuca - México

Es sabido que los Albers profundizaron en sus investigaciones la cuestión de la ilusión óptica. Hay una fotografía de Josef Albers, aún del período alemán, sin título (Ropa en una soga), circa 1929 (Fig. 7), absolutamente coincidente con una anterior, obtenida por Mário de Andrade en su viaje etnográfico por el nordeste brasileño, a partir del cual redactaría no sólo Macunaima (I928) sino su libro póstumo El turista aprendiz (2015). Hay además una tercera foto, de Man Ray, Sculpture mouvante ou La France (1920), de idéntica composición y que fue tapa de la revista La Révolution Surréaliste en 1926, hoy rescatada por Didi-Huberman en su exposición Sublevaciones (Muntref 20I7). Pero me detengo en la de Mário 
de Andrade: también de ropas henchidas por el viento y colgadas de un alambre, está subscripta: «Roupas freudianas/Fortaleza, 5-VII-27/ Fotografia refoulenta/Refoulement/Sol 1 diaf. 1» (Fig. 8). Mário acusa así la relevancia y estímulo de cierto debate incipiente sobre la formación cultural de Brasil en la colonia. Concretamente, en una conferencia en la Sorbonne de 1923, Oswald de Andrade ya se había referido al recuerdo sexual de la mujer blanca, que los primeros navegantes dejaron en Portugal a la espera de sus inciertas expediciones. Por esa misma época, Mário de Andrade lee el tratado de psicoanálisis en el arte de Charles Baudouin (1972), ${ }^{3}$ que define la sublimación (refoulement) como desplazamiento, a veces muy cargado y débilmente inhibido que, como acto sobredeterminado, actúa sobre vías de reacción que a su vez poseen valores espirituales, morales o sociales dominantes, de lo cual Baudouin infiere que el arte, en cuanto refoulement, tendría la fun-

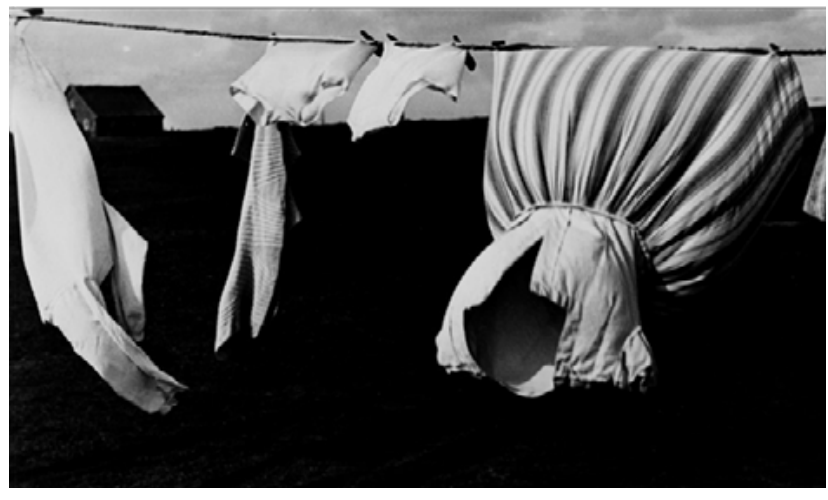

Fig. 7 Josef Albers - Clothes - ca I929

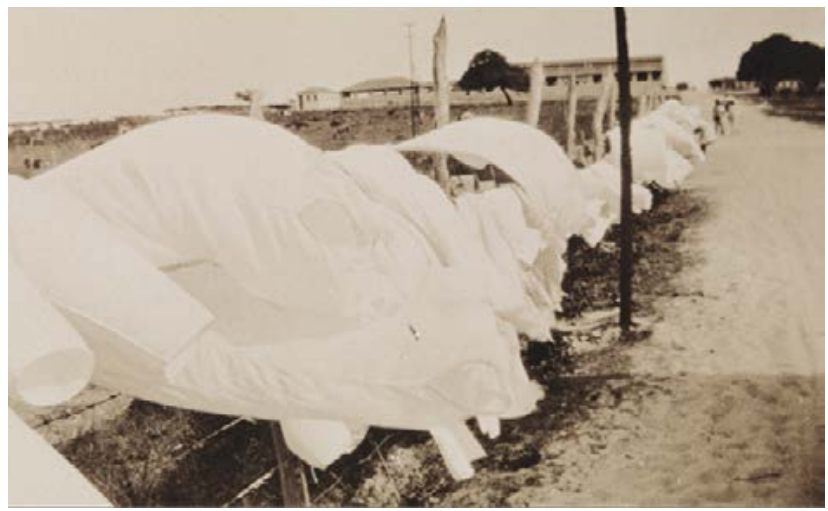

Fig. 8 Mário de Andrade - Roupas freudianas ción de realizar o estimular sublimaciones. Las ropas freudianas, refoulentas (y véase que en el neologismo creado por Andrade entran, a través del sufijo -lentas, la noción de suspensión o atraso originario, así como la de una locura que sería inherente a las multitudes (foule), las cuales desplazarían hacia otros objetos la agresividad de una sociedad de advenedizos (primero los colonizadores, y luego los inmigrantes), que en el reparto de capital se habrían quedado sin mujeres. La anotación nos muestra además que es el vacío fantasmático que agita esos semblantes, las ropas, lo que lo lleva a Mário de Andrade a elaborar una tesis que llamará «el secuestro de la mujer ausente». Hay indicios, como una carta al poeta Manuel Bandeira de 1928, que nos persuaden de que la hipótesis ya estaba siendo construida en ese momento. Una de sus divulgaciones posteriores se daría en noviembre de 1937, en la sociedad de etnología y folklore de San Pablo, donde se destacaba, precisamente, a la mujer ausente, Dina Dreyfus, ${ }^{4}$ insigne antropóloga francesa que llegara al país con su por entonces mucho menos conocido esposo, Claude Lévi-Strauss. Andrade la reitera en 1943 en la revista luso-brasileña Atlântico, pero esa repetición no deja de ser complejamente sintomática. Mário de Andrade elabora en efecto una teoría de la cultura nacional poscolonial, pero la destina al Poder (una revista fascista, Atlântico), a la tradición (Salazar no es un modernizador, porque su ideal de cultura no está en las grandes ciudades, sino en la pequeña aldea portuguesa) y la enuncia en nombre del patriarcalismo heterosexual (pero de mujer ausente), con lo cual su discurso dice más de lo que afirma. Dice, contra el poder, la tradición 
y la familia, que Brasil fue construido a partir de sociabilidades homoafectivas que fueron reprimidas por refoulement para que un valor sublime, la patria, lo patriarcal, allí tuviese lugar. Como se ve, la hipótesis de Andrade connota una versión, en su extremo, bastante conservadora, porque descansa en lo homogéneo y adaptativo, cuando, por el contrario, contemporáneamente, entendemos que el arte surge justamente cuando todo aquello que no puede ser dicho, admite sin embargo ser mostrado e incluso exhibido, con ostentación nada púdica, tal como las ropas en la cuerda.

Si en la imagen de Andrade el punctum de la sobrevivencia descansa en lo blanco o neutro de la ropa, espectralmente agitada y completada por el viento, el desafío para Albers, igualmente obsesionado por el mismo fantasma de exilado, sería el de aislar, a continuación, los espectros de color. En efecto, explorando, junto a los Dreier, en la escuela de Carolina del Norte, los sistemas cromáticos de Johann Wolfgang von Goethe, Arthur Schopenhauer y Friedrich Wilhelm Ostwald, Albers llega a decir que la sobrevivencia (lo que Aby Warburg hubiera llamado Nachleben pero Albers denomina after-image o contraste simultáneo) es un fenómeno psico-fisiológico que nos muestra que ninguna mirada normal, ni siquiera la del ojo entrenado es, ante la inevitable decepción cromática, infalible (Albers dice foolproof, con el mismo tono radical que dice refoulement). Aquel que dice ver los colores con prescindencia de sus cambios ilusorios se engaña (fools) a él mismo y a nadie más que a sí (Albers 1979).

\section{$* * *$}

La posición de Albers es claramente una impugnación a la idea de armonía (defendida entre otros, por Le Corbusier con su modulor, de profunda influencia en la definición brasileña, autónoma y funcionalista, de lo moderno) y coincide además con las ideas de John Cage, no sólo en su conferencia de Juilliard, sino en una obra como 4'33", su pieza-manifiesto, en donde el silencio (el vacío de las ropas refoulentas para Andrade o el vacío abstracto para Albers) no es exactamente la ausencia de sonido sino el reconocimiento de otros barullos incidentales o ambientes, no deliberados. ${ }^{5}$ Así, para Albers, el color no funciona sino que existe, lo cual, amén de revelar el peso de las ideas dadaístas o zenbudistas entre los artistas de Black Mountain, encendería la ira de un Adorno.

En efecto, la problemática del color, en términos de variación y repetición, dialoga y se confronta con la cuestión de la armonía musical porque, aunque ambas presupongan un hipotético modelo originario al que estarían mutuamente referidas, el serialismo reemplaza al contrapunto y así la génesis es substituida por la arkhé, la emergencia. Esto acarrea que el paradigma de la distancia crítica, sustentado por los frankfurtianos, y que presupone siempre un sujeto autónomo, cuando no soberano, descanse, no obstante, en la estructura de una sociedad capitalista, en este caso, para colmo, colonial, donde no deberían existir complejas metamorfosis. En cambio, la lectura neovanguardista que Albers nos da de Mitla reformula, a la luz de la escena posbélica, el legado de las vanguardias históricas. 
Más que de una subjetividad revolucionaria, cuya tarea sería debilitar los valores de una expansiva cultura burguesa de masas, su percepción de una forma de existencia visionaria, que exigiría una nueva sociedad, acarrea una noción de la diferencia que desestabiliza la lógica ejemplar de la repetición o de la dilución, porque solo así, por la vía de la interrupción o suspensión, la anhelada anarquía podría finalmente rearmar los lazos simbólicos de una nueva sociabilidad.

\section{$* * *$}

Un ejemplo aún más elocuente nos lo brinda Anni Albers. La artista teje en $1947 \mathrm{La}$ Luz I (Fig. 9), una trama de algodón e hilo metálico (47 x 82,5 cm), cuyo nombre, en castellano, nos alerta sobre su origen. Comienza a partir de I95I una duradera colaboración de diseños para la fábrica textil Knoll, algunos de los cuales ilustran que Mitla despierta en ella nuevos abordajes de telar como, por ejemplo, Study for Camino Real (I967; acuarela sobre papel 44,4 x 40,6 cm, Fig. IO) o $D R X X$ (I974; tinta y lápiz sobre papel, 25,375 x 19,625 cm, Fig. II). El hecho de que Anni Albers trabajara principalmente en telar nos abre asimismo una dimensión más allá de lo visual, háptico-óptica, que rescata las ideas de Alois Riegl, algo crucial para el espíritu Bauhaus de los años 20. Pero si la tactilidad de Riegl podría ser encarada como precursora de una Kunstwollen óptica, no es menos cierto que las experiencias fotográficas de Moholy-Nagy, Otti Berger y Gunta Stölzl, documentando los tejidos Bauhaus, preparan una percepción visual de la trama, de tal

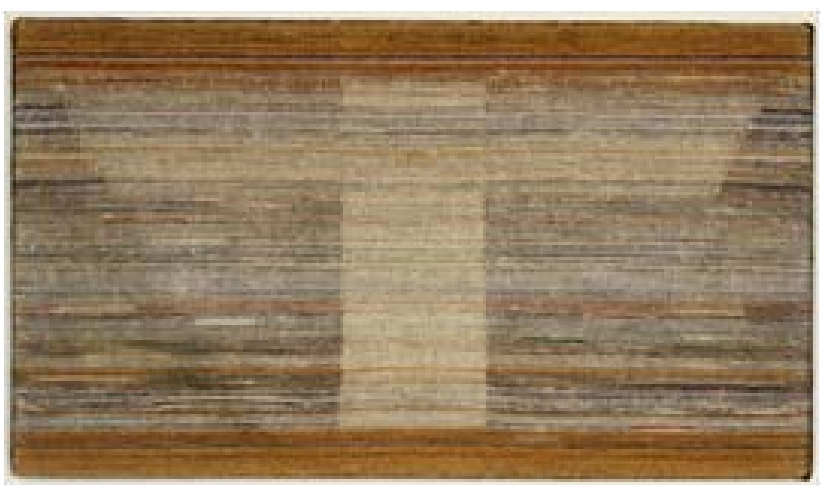

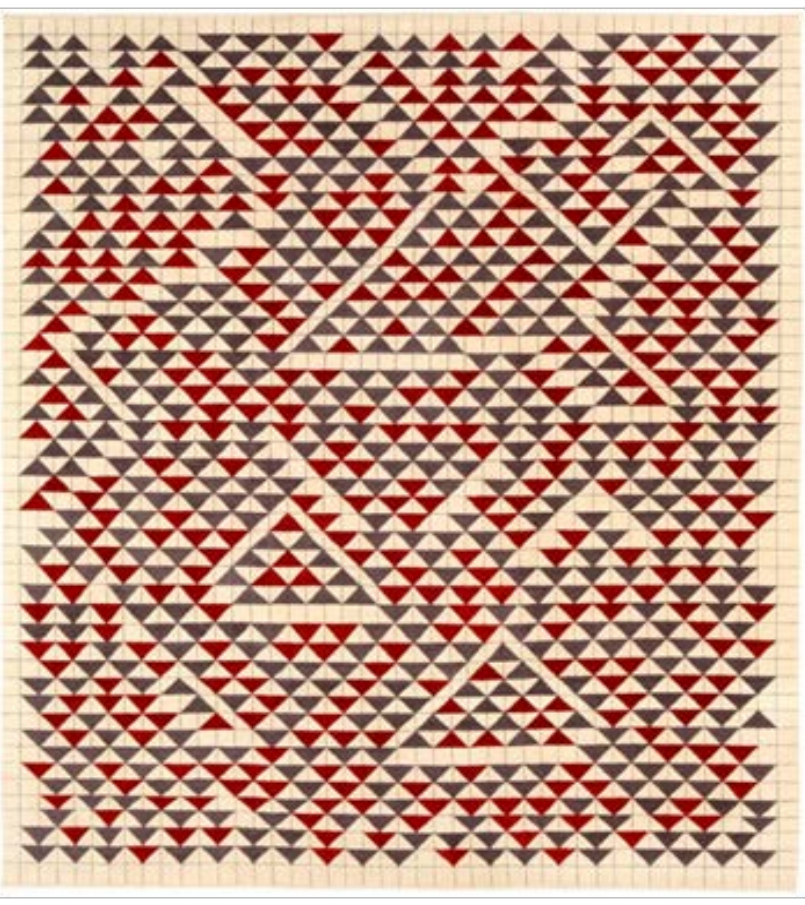

Fig. Io Anni Albers - Study for Camino Real - 1967
Fig. 9 Anni Albers - La luz I - I947

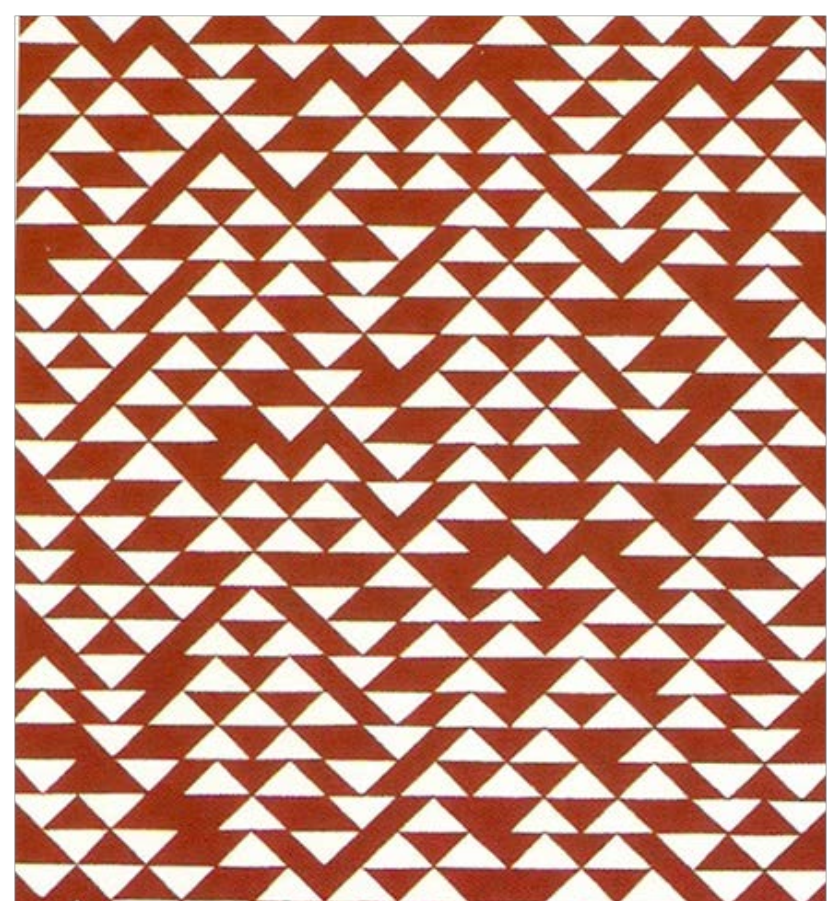

Fig. II Anni Albers - DR Xx - I974 
suerte que sus fotografías funcionan como una lente a través de la cual el tejido (el texto como tejido de voces) puede finalmente ser apreciado y circular. $\mathrm{O}$ sea que, contrariamente a lo que argumenta la hegemonía visual, reivindicada por la autonomía funcionalista, la tactilidad es central a esta experiencia, porque ayuda a que la imagen ocupe su lugar en los circuitos de consumo (Smith, Scocco:I93-196).

En 1934, Arturo Capdevila y Julián García Velloso componen un libro de lectura para la escuela primaria (1936). ${ }^{6}$ Lo ilustra, en blanco y negro, Wladimiro Acosta, arquitecto georgiano arribado al país en 1928, bastante marginal en el contexto de la historiografía arquitectónica argentina, aunque sus experiencias fotodinámicas hayan sido prontamente acogidas en la revista Sur (I933:I43-I44). La arquitectura racionalista tuvo un aspecto decisivo en sus aportes sobre arquitectura y clima, el sistema Helios, a través del cual se analiza las cualidades metafísicas de la luz y su relación con las formas físicas (Liernur, Sarlo, AA. vv.). En Patria Grande, el libro de lectura para las masas escolarizadas en primaria, Acosta ilustra una serie de fachadas coloniales, no tan imponentes como Mitla pero imprescindibles para el patrimonio nacionalista que los autores quieren constituir y divulgar: antes de Berni, muestra Jujuy (Capdevila y Velloso:23), Catamarca («Catamarca») (52), Salta («Una puerta de la libertad») (62), la que «se hace solidarias señales con Quito, con Bogotá o El Salvador», La Rioja («La dulce Rioja») (69), Mendoza en I86I, la recova del Cabildo o la casa del virrey Sobremonte («La casa colonial») (III). ${ }^{7}$ Pero hay allí una imagen que me gustaría destacar. Se trata de dos jugadores de ajedrez enfrentados ante el tablero que, gracias a la luz perpendicular, adquieren una inquietante textura táctil. El texto es elocuente. Allí se lanza una apuesta que requiere ir de lo material a lo inmaterial. Es la vida misma que está en juego. ${ }^{8}$

Los dos jugadores de ajedrez están frente a frente, dotados de idénticas posibilidades. Peones, caballos, alfiles: todo es igual. ¿Cuál triunfará? Uno resultará muy pronto superior al otro: pero esta superioridad no será ni casual ni arbitraria, sino perfectamente justa. El que resuelva mejor sus problemas será siempre superior.

Lo mismo que en la vida. Todo es problema en ella; pero todo es equidad y todo es ley.

Hemos jugado nuestra pieza. ¿Qué hará el adversario? El mero paso de un peón puede modificar completamente las posiciones y ser causa de victoria o de derrota. Lección incomparable que nos muestra que todo acto en la vida debe ser bien meditado. (Capdevila y Velloso:236-237) ${ }^{9}$ (Fig. I2)

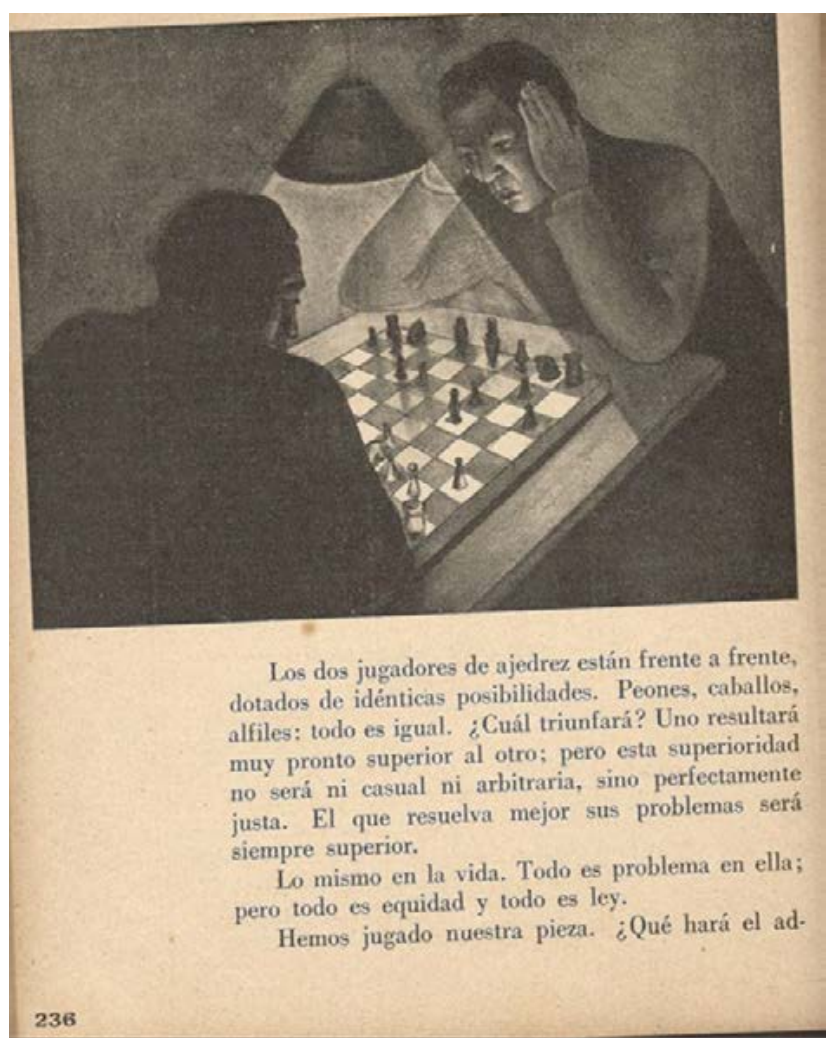

Fig. 12 W. Acosta - Jugadores de ajedrez 
$* * *$

Cuando Caetano Veloso recibió una estrepitosa silbatina (vaia) en un festival internacional de música, en el auge de la dictadura, 1968, al interpretar «Es prohibido prohibir», Augusto de Campos creó el poema-manifiesto Viva a vaia, un texto óptico-verbal que anticipa en algunos años el $D R X X$ de Anni Albers. Por tanto y muy a pesar de que las experiencias de Albers sean reivindicadas en el plan piloto de la poesía concreta (1958), no es que estemos en rigor, en Viva a vaia, ante una influencia de lo visual sobre lo verbal, sino que aquí nos deparamos con un objeto cuya misma legibilidad se derrama por más de una disciplina. Más aún, invirtiendo el razonamiento: si examinamos un borrador del poema, es posible abordar ese manuscrito como si fuera una suerte de Gran Vidrio duchampiano (Fig. 13). En efecto, sabemos que en la desobra abandonada por Duchamp hay, en la zona inferior del vidrio, nueve hombres: un sacerdote, un mensajero, un soldado, un gendarme, un policía, un jefe de estación, un criado, un repartidor y un sepulturero. Todos ellos tratan en vano de llegar a la mujer ausente y son manipulados, como marionetas, por un complejo mecanismo de hilos y alambres, la máquina antropológica. Henchidos por el tiempo, se mueven en un espacio tenso y liso, a la vez, abriéndose a la indecidible mirada, tanto de ella como de sí mismos. Aunque separados por una infranqueable lámina de aluminio, de tal suerte que todos están condenados perpetuamente a la soledad y al anonimato, mientras la mujer ausente sostiene el hilo de su indomable soltería, ellos en cambio salpican su erotismo por todas partes.

La desobra de Duchamp, al igual que Viva a vaia (Fig. I4 y I5) de Augusto de Campos, desconstruye las eternas apariencias hegemónicas, desactivando la voluntad, orientada ahora hacia la virtualidad de la aparición de un complejo palabra-imagen-objeto. ${ }^{10}$ El lenguaje del Gran Vidrio opera así con la conspiración del silencio, susurro incesante entre imagen y palabra que cuasi configura un gesto litúrgico, de puro simulacro y potencialidad. De este modo emerge, en la desobra, el lenguaje del pensamiento, es decir, el discurso de lo que pende eternamente sin identificarse, de modo cabal, ni con la voz ni con la vocación, el apelo.

Según el mismo Duchamp, con los moldes, tamices y la espiral elíptica del vidrio, se cuestiona la apariencia y surge en cambio el principio de la aparición en superficie. Recordemos que la apariencia es el conjunto de datos sensoriales que permite imaginar un objeto. La aparición,

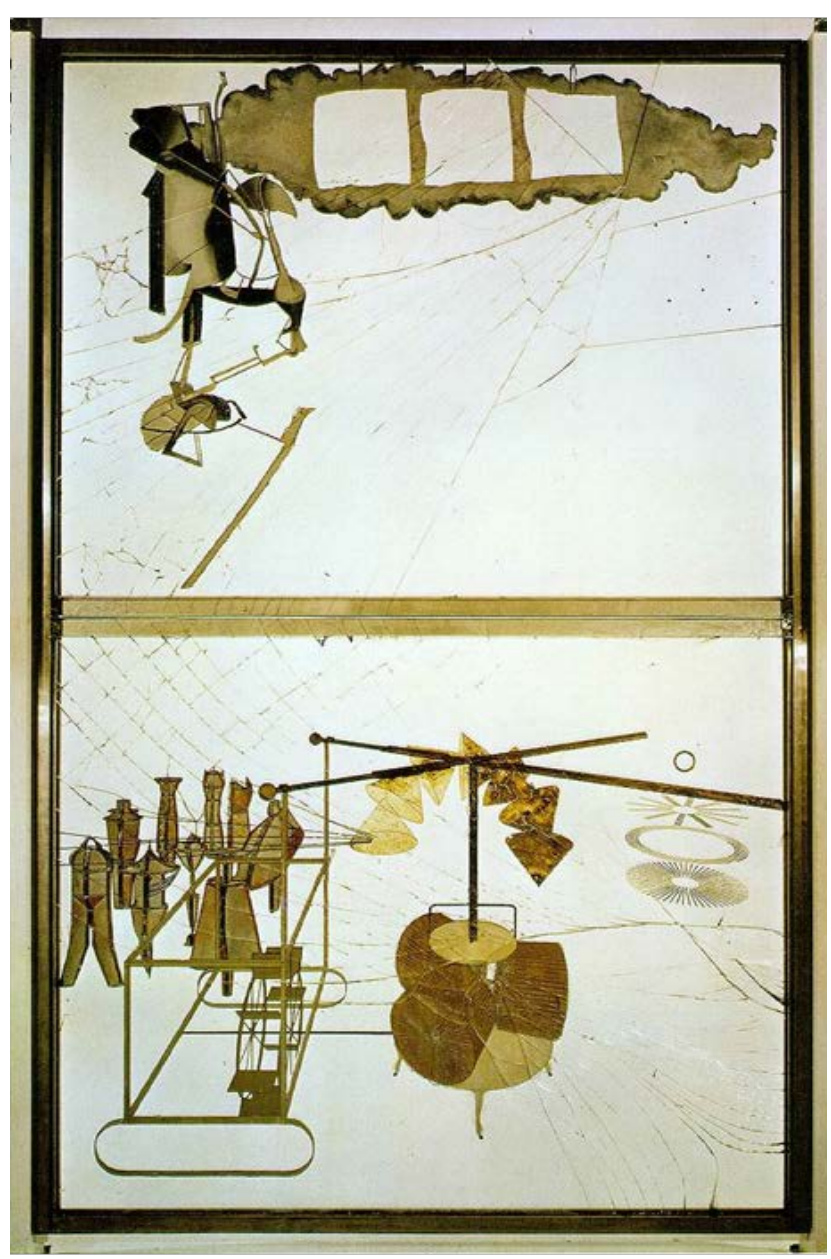

Fig. I3 Marcel Duchamp - La novia desnudada por sus solteros o El gran vidrio - I9I5-1923 - Philadelphia Museum of Art 
sin embargo, es la imagen en $\mathrm{n}+\mathrm{I}$ dimensiones de los puntos capitales del objeto. Es un molde que permite la construcción del objeto. Es el reverso mismo de la imagen de ese objeto. Por lo tanto, si el Gran Vidrio es una archi-escritura que desconstruye la apariencia en nombre de la aparición, bien podemos leer Viva a vaia como un poema-archivo.

En efecto, si observamos el manuscrito, en la zona inferior hay un mensaje de los solteros, AMOR/HUMOR, que no es sino una cita del poema paronomásico de Oswald de Andrade, con la salvedad de que Augusto sobreimprime una cruz en la $\mathrm{H}$ (la cruz que subyace al plan piloto de Brasilia, la cruz ante la que se curvan portugueses e indígenas en la Primera misa en Brasil, el cuadro emblemático de Victor Meirelles, I86I). Levantando la mirada, en el rincón superior derecho, leemos, en vertical, vIVA / ALI VAI A / AVIDA / DIVIDA / LIVIDA / ALI VAI A / DICA / CADA DIA, o sea, he ahí la ávida deuda lívida, he ahí el consejo a cada día. Enfrentada a esa cifra de la dependencia y deuda externa, se destacan tres significantes, DADIVA MORTE WORLD. En el centro umbilical de la constelación, el eje en torno al que rueda ese pergamino, el significante GRAVIDA (que a su vez remite a otro juego onomástico concreto, hombre-hembra-hambre) y, a su derecha, encolumnado con el relato de la deuda, la
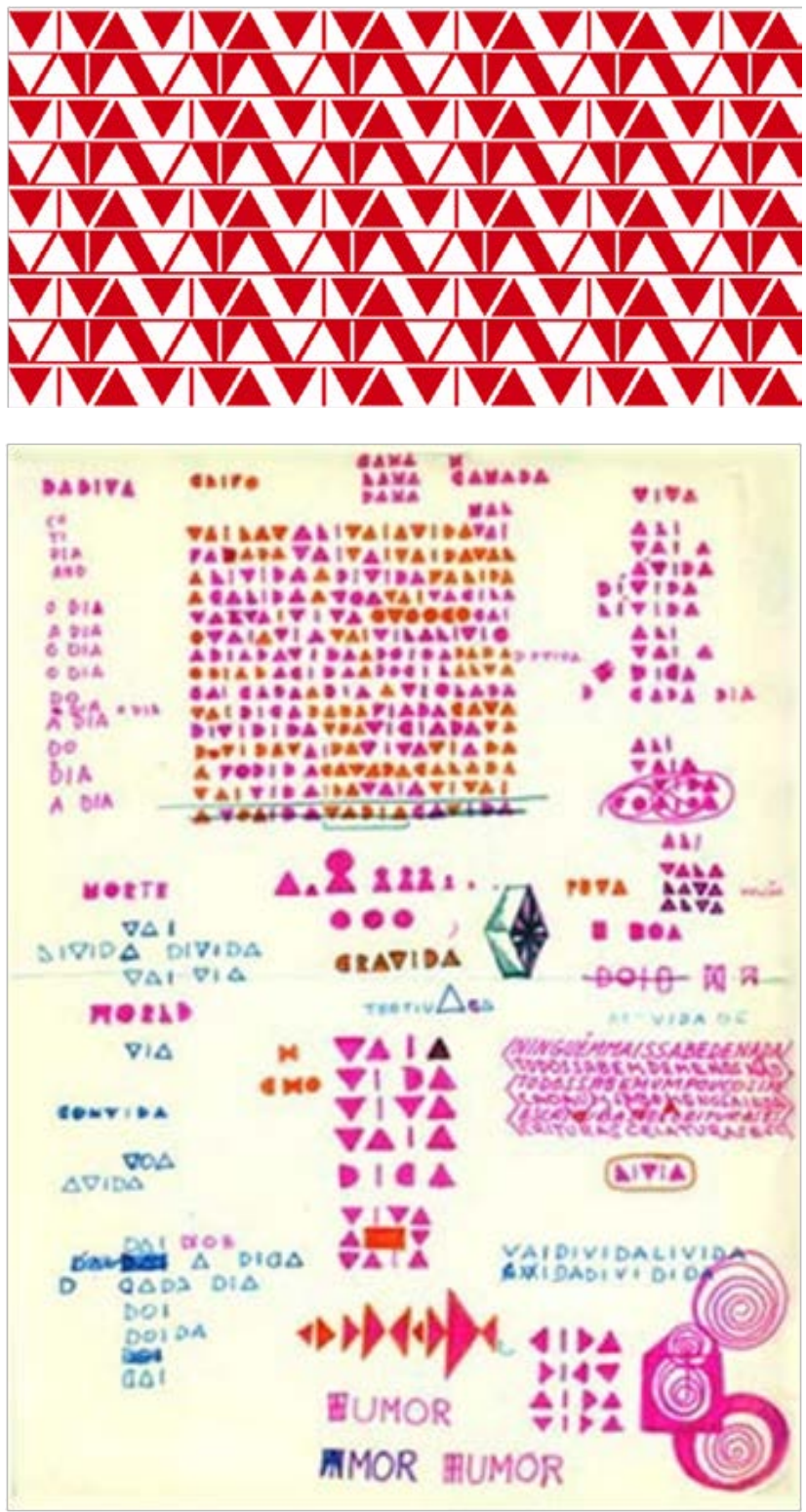

Fig. I4 Augusto de Campos - Viva a vaia - 1972 dispersión de otros tres significantes, VALA LAVA ALVA, que sobreimprimen la antiquísima cantiga de amigo del rey Dom Denis (I26I-I325), suerte de tributo a Alfonso x y la tradición occitana, en que una bella muchacha se levanta al alba («levantou-s'a velida») y fue a lavar camisas a un riacho, pero el viento le agita las piezas, lo que la irrita sobremanera («vai lavar camisas;/ levantou-s'alva,/ o vento lhas desvia/ eno alto,/ vai-las lavar alva»). La reliquia, que sobrevivirá incluso en Morenita de Ronda, de Federico García Lorca (aunque el poeta admita, entre paréntesis, que «yo no soy para esos labios») nos muestra que, donde comenzó la literatura en lengua portuguesa, es asimismo donde se diluye su lirismo para permitir, justamente, la emergencia de la literatura como exigencia.

\section{$* * *$}

En abril de 1933, Arturo Capdevila redacta unas palabras preliminares en Patria Grande dirigidas a los maestros: 
En la clase, una voz nunca oída — la voz del maestro, la voz de la maestra- resonará profundamente en el alma infantil. El buen escolar se entregará a un arrobo religioso oyendo ese acento. En un éxtasis escuchará esa música incomparable de la iniciación en la verdad.

Está bien. Pero quisiéramos, de veras, que estos niños adquiriesen desde hoy mismo el primer sentimiento y la primera noción de una vida responsable y digna. Porque el patio de la escuela se asemeja mucho más de lo que se supone a la plaza de la ciudad. Acostumbrar a los niños desde temprano a que respondan de sus acciones y palabras, en la justa medida de su capacidad, vale tanto como enseñarles a leer.

Por eso queremos que desde temprano nazca y crezca en cada uno el sentimiento de la responsabilidad. Tener bien neto este concepto conduce de por sí a llevar cuentas honradas con el destino. Los pueblos que se preparan a una hercúlea acción deben llevar honradamente estas cuentas. Dejar de vivir como en los sueños; dejar de ser juguetes de pueriles contingencias; pensar los actos; medir las palabras; meditar y revisar los juicios; limpiar la voluntad, acrisolar los anhelos; hacer cotidiana gimnasia, desnudo el busto, bajo el clima fuerte de la responsabilidad; querer averiguar con certeza quiénes somos y de qué somos capaces; contar con nosotros mismos; todo eso es, en lo privado y en lo público disponerse de veras al cumplimiento de un extraordinario destino.

¿Acaso la vida de este pueblo no dejará memoria? ¿Acaso el hombre escribirá sobre el agua su pensamiento? ¿Acaso nuestros hechos serán como humo en el aire? Yo no veo otro camino para aprontarse a ser algo, que el muy áspero — sí, pero muy seguro— de la responsabilidad. (Capdevila y Velloso:XIII-XIv)

La reflexión trascendental de la pedagogía se representa, más allá de la acción recíproca de sujeto y objeto, como una actividad del sujeto que no depende de él. Es un yo colectivo, tomado en cuanto sustancia, lo cual puede evaluarse como una imposibilidad efectiva de pensar lo singular. Capdevila hace descansar el esfuerzo cívico de Patria Grande en un imperativo, la responsabilidad, el poder responder por la totalidad de los ciudadanos. No es en nada comparable a lo que los Albers o Augusto de Campos nos proponen. La apuesta de estos artistas se orienta en cambio hacia la exigencia, que podríamos definir no como una categoría moral sino ontológica. Es, de hecho, una categoría de la memoria, tanto para Eugeni D'Ors como para Cage. No se adapta a los hechos, ni sueña con ideales. Como la posibilidad y la imposibilidad, o bien la necesidad y la contingencia, es la exigencia una categoría modal que nos propone sin embargo un tercer género (la khora semiótica), el vacío donde las cosas llegan a ser, e indica la ausencia de una posibilidad. Giorgio Agamben la define como un estado de complicación extrema de la verdad que implica ser o asumir todas las posibilidades, de tal suerte que la exigencia es y no es, al mismo tiempo. En otras palabras, la exigencia es el sueño del acto. Es refoulenta.

Para esta perspectiva, el ser no se apropia de formas de vida ya existentes, como quiere la pedagogía de Capdevila; se despliega en ellas, las desarrolla, como contraste simultáneo o modificación incesante. Pero como exigir (exigere) no es implicar (involvere), diríamos que la misma literatura exige ser leída de una manera 
creativa, en más de un abordaje, aunque nadie así la lea, o sea que, en la medida en que demanda ser leída de otra manera, la literatura es siempre y por principio algo ilegible y, en ese caso, el lector ya no es sólo discontinuo, como pretendían las vanguardias históricas, sino incluso inexistente, con la salvedad de que su misma existencia, fruto de la exigencia, está siempre referida a un antecedente y proyectada a un consecuente, porque la exigencia une y separa, simultáneamente, tiempos disímiles. La exigencia no limita sino que abre umbrales.

En ese sentido, entonces, diríamos que la exigencia de una comunidad sin presupuestos que mantiene, sin embargo, y quizás sin darse cuenta, la forma vacía de la presuposición, más allá de todo fundamento, es algo que atraviesa el pensamiento crítico de Maurice Blanchot, Jacques Derrida, Jean-Luc Nancy y Giorgio Agamben. Este último, en particular, ha hecho un uso recurrente del concepto de exigencia. La máquina mitológica de Furio Jesi, por no ser un paradigma distante, situado entre el sujeto y el objeto, sino que involucra la estructura misma del sujeto que conoce, llegó a ser comparada por Agamben a una colada por cera perdida, ${ }^{11}$ que reproduce exigencias y necesidades de la materia, pero las plasma como un nuevo lenguaje específico. El atlas de la memoria de Warburg es también para el filósofo la exigencia de una ciencia más amplia, para la que Warburg siquiera supo encontrar un nombre definitivo, pero a cuya configuración se dedicó tenazmente hasta la muerte. En El uso de los cuerpos, Agamben recuerda a Gottfried Wilhelm Leibniz, quien define la existencia como una exigencia de la esencia, omne possibile exigit existere. ${ }^{12} \mathrm{El}$ ser es una pura exigencia tendida entre el lenguaje y el mundo (20I4b:8I-86). No es una simple posibilidad, sino un modo de la potencia en la medida en que, si la existencia es una exigencia de la posibilidad, entonces la posibilidad se vuelve una exigencia de existencia. En otras palabras, lo posible se vuelve necesario. Más recientemente, en ¿Qué es la filosofia?, Agamben rescata la idea de ser la exigencia (tal como la justicia) una categoría ontológica y precisa que, cuando en la séptima proposición del tercer libro de la Etica, Baruch Spinoza dice «Conatus, quo unaquaeque res in suo esse perseverare conatur, nihil est praeter ipsius rei actualis essentia», o sea, el esfuerzo con que cada cosa intenta perseverar en su ser no es nada distinto de la esencia actual de la cosa misma, estamos ante algo que supera lo simplemente imperativo. Por eso Agamben propone traducir conatus no como esfuerzo sino como exigencia y, valiéndose del comentario del mismo Spinoza que asocia conatus con cupiditas, es decir, el deseo, estamos diciendo que la exigencia no tiene objeto, es decir, la exigencia se aproxima así a la antifilosofía de Jacques Lacan (Agamben 20I6:47-56). La exigencia acaba por esta vía reinscripta en el Gran Vidrio del pensamiento, haciendo que la eternidad supere así al infinito, justamente, porque, al ser inolvidable, la vida inmortal, aún cuando no disponga de memorial o testimonio es lo que cuenta y no debe ser olvidada: es la ávida deuda lívida, el consejo nuestro de cada día. ALI VAI A / AVIDA / DIVIDA / LIVIDA. 


\section{Notas}

1 Rojas retomará esa cuestión en Silabario de la Decoración Americana (1930) (Ver también Fiadone). Carl Einstein llegó a analizar en 1922 un tapiz peruano en el que detecta, más allá de la influencia hispánica, un esfuerzo de formalización que pasa por la combinatoria de siete elementos, algo que luego se aplicaría al tejido de los ponchos para lo cual Einstein remite a Ambrosetti, probablemente al pasaje de Supersticiones y leyendas en que se mencionan los floreos como diseños del telar para la confección de los ponchos de vicuña (172).

${ }^{2}$ En carta a Ricardo Rojas, Guido se refiere al entierro de Hipólito Yrigoyen, anticipando los tópicos de sociología sagrada que el Colegio de Sociología exploraba también por aquel entonces. «La expresión popular de casi medio millón de almas tiene para mí una gran significación: que el pueblo argentino es un pueblo romántico por excepción. El homenaje al presidente caído y de mi partido que no puede repartir empleos tiene, creo, un significado tremendo como pueblo capaz un día de asumir aquella actitud alta y romántica que los grandes orientadores tendrán la obligación de dar a nuestra patria en un futuro muy próximo» (Guido).

${ }^{3}$ La traducción es de Marcos Fingerit, estrecho amigo de Macedonio Fernández.

${ }^{4}$ Dina Dreyfus (I9II-I999) nació en Milán y llega a París en 1924. Entre 1935 y 1938 participa con su marido de una misión etnográfica en Brasil. Allí lo conoce a Andrade con quien funda la Sociedad de Etnología y Folklore en 1936. En una reseña para la Sociedad de Americanistas (Lévi-Strauss:429-43I), Dina explica que «la Société d'ethnographie et de folklore est le premier organisme de ce genre existant au Brésil. Elle est un centre de recherches collectives, et repose sur la base de la coopération intellectuelle, théorique et pratique, d'un grand nombre de chercheurs. Elle s'inspire par là des tendances actuelles des institutions similaires du monde entier et plus particulièrement des institutions ethnographiques et folkloriques françaises (Institut d'ethnologie de l'Université de Paris, Département des arts et des traditions populaires, Société de folklore français et colonial, Commission de recherches collectives, etc.), dont elle suit attentivement les travaux et les résultats. Sa création est due à l'initiative de M. Mario de Andrade, directeur du Département de culture de la municipalité de São Paulo, son président actuel, à l'impulsion de qui les études folkloriques brésiliennes doivent leur développement. Le Département de culture a maintenu durant l'année 1936 un cours d'ethnographie pratique; en accord avec les étudiants et auditeurs de ce cours, il a fondé, l'année suivante, la Société d'ethnographie et de folklore, dont le but est d'encourager, d'orienter, de promouvoir et de divulguer les études ethnographiques anthropologiques et folkloriques. A cette fin, elle s'est efforcée d'organiser une coopération effective entre ses membres, les groupant en vue de recherches et de travaux collectifs; d'effectuer des réunions et des voyages d'études avec un programme déterminé; d'entrer et de se maintenir en contact avec les institutions similaires, nationales ou étrangères; de subventionner, éventuellement, des collections ethnographiques et folkloriques ; enfin de réaliser des conférences, des cours et des publications». Sus órganos de difusión eran la Revista do Arquivo Municipal y un boletín específico de la sociedad, de circulación más comedida. Tras la experiencia, Dina Dreyfus retorna a Paris en el '39, participa de la resistencia en la región de Montpellier y finalmente se divorcia de Lévi-Strauss en el '45. Después de la guerra pasa a enseñar filosofía y dicta cursos con Vladimir Jankélevitch. En 1963 edita una antología de textos de Sigmund Freud por las Presses Universitaires de France y, entre 1964 y 1968, innova en la enseñanza de la filosofía por televisión con la asistencia de Alain Badiou, Georges Canguilhem, Michel Foucault, cuyos talentos supo discernir (ver Dreyfus, Spielmann).

${ }^{5}$ Cuando Cristina Peri-Rossi traduce los cuentos de Onde estivestes de noite? de Clarice Lispector opta por el título genérico, muy John Cage, de Silencio (1988), comprendiendo quizás lo que Lispector se proponía en esos relatos, la anti-literatura de la cosa, la designación del objeto-causa del deseo. «Para além da orelha existe um som, à extremidade do olhar um aspecto, às pontas dos dedos um objeto - é para lá que eu vou», nos dice Clarice en uno de esos relatos, porque «à beira da família estou eu. À beira de eu estou mim. É para mim que eu vou. E de 
mim saio para ver. Ver o quê? ver o que existe». Toda vida, para Clarice, es en última instancia vida póstuma: «eu sou nada. Depois de morta engrandecerei e me espalharei, e alguém dirá com amor meu nome. É para o meu pobre nome que vou». (Ver también Branden:80-IO4).

6 Junto a Julián García Velloso, Capdevila (I8891967) publicó también otros libros de lectura, Nueva jornada (1937), Florecimiento (1942) y Ruta gloriosa (1957).

7 El dibujo de Wladimiro Acosta traduce una fotografía de Alfredo González Garaño que a su vez había ilustrado un artículo de divulgación del gran reivindicador del estilo colonial (Noel).

${ }^{8}$ En 1941, Stefan Zweig publica su última novela, Die Schachnovelle, la novela de ajedrez, donde exilio y excepción también aparecen cifrados en la apuesta. Maria Helena Vieira da Silva, también exilada, como Zweig, en Río de Janeiro, pintaría muchas telas en que la temática del ajedrez confluye con la biblioteca como un damero infinito que comporta innumerables combinaciones.
9 «Una lección de ajedrez».

10 Clarice Lispector la llamaría «objecto-relatóriomistério", objecto con ct, escrito a la manera portuguesa, y no brasileña, como revival incesante de lo que no cesa de no escribirse. Esa tríada había sido pensada por Clarice como título para su cuento «O relatório da coisa", es decir su manifiesto de una anti-literatura de la causa del deseo.

${ }^{11}$ La cera perdida es la técnica de la infinita libertad con que Maria Martins crea sus figuras informes y trata de persuadirlo a Duchamp para usarla en la muñeca de Dados.

12 «Quando, qualche decennio piu tardi, Leibniz definira l'esistenza come una esigenza dell'essenza e, nella corrispondenza con Des Bosses, scrivera che il vincolo, che definisce l'esistenza delle sostanze composte, 'esige le monadi, ma non le implica essenzialmente', e con questo stesso problema che egli sta cercando di misurarsi» (Agamben 20I4a:206).

\section{Bibliografía}

AA. vV. (2008). Wladimiro Acosta 1900-1967. Madrid: T6 ediciones.

aCosta, Wladimiro (I933). «El mundo de los hombres invisibles». Sur 7, I43-I44.

albers, Josef (1979). La interacción del color. Madrid, Alianza. Traducción de María Luisa

Balseiro.

(2006). Anni y Josef Albers. Viajes por Latinoamérica. Madrid: Museo Nacional de

Arte Reina Sofía.

agamben, giorgio (20I4a). L'uso dei corpi. Homo sacer. IV, 2. Vicenza: Neri Pozza.

(20I4b). «Sulla dificoltà di leggere». Il fuoco e il racconto. Roma: Notttempo, 8I-86.

(2016). «Sul concetto di esigenza». Che cos 'ê la filosofia? Macerata: Quodlibet, 47-56.

ANDRADE, MÁRIO DE (2OI5). O turista aprendiz. Telê Ancona López y Tatiana Longo Figueiredo,

editores. Brasília: IPHAN.

Baudouin, Charles (1972). Psicoanálisis del Arte. Buenos Aires: Psique. Traducción de Marcos

Fingerit.

BRANDEN, W. JOSEPH (I997, verano). «John Cage and the Architecture of Silence». October, Vol. 8I, 8O-IO4.

Benjamin, Walter (1999). "Some remarks on Folk Art», Selected writings. Vol. 2, 1927-I934.

Trans. Rodney Livingstone y otros. Michael W. Jennings, Howard Eiland, Gary Smith, editores. Cambridge: The Belknap Press of Harvard University Press, 278-279.

Best MaUgard, adolfo (1923). Método de dibujo: tradición, resurgimiento y evolución del arte mexicano. México: Departamento Editorial de la Secretaría de Educación. 
capdevila, arturo y julián garcía velloso (1936). Patria Grande. Evocaciones, estampas, escenas, descripciones. 6a ed. Ilustraciones Wladimiro Acosta. Buenos Aires: Kapelusz.

Carpentier, alejo (1976). "De lo real maravilloso latinoamericano». Tientos y diferencias. Buenos Aires: Calicanto, 83-99.

- (1984). «Lo barroco y lo real maravilloso». Ensayos. La Habana: Letras Cubanas, I08-126.

DReYfus, Dina (2013). Écrits. Christiane Menasseyre y Bertrand Saint-Sernin, editores. París: Hermann.

CURT LANGe, francisco (1938). Impresiones andinas. Montevideo: Nueva América.

einstein, CARL (1922). «Peruanisches Bildgewebe der Sammlung Gans». Das Kunstblatt 6, I72. FIADONE, ALEJANDRO E. [1922] (200I). El diseño indígena argentino. Una aproximación estética a la iconografía precolombina. Buenos Aires: La Marca.

guido, alfredo (1933). Carta a Ricardo Rojas. Los Angeles, I9 ago, 1933. Archivo de la Casa Museo Ricardo Rojas.

guido, Ángel (1927). Carta a Ricardo Rojas. Rosario, 24 jul. 1927. Archivo de la Casa Museo Ricardo Rojas, Buenos Aires.

(1930). Eurindia en la arquitectura americana. Santa Fe: Universidad Nacional del Litoral.

(1940). Redescubrimiento de América en el Arte. Rosario: Universidad Nacional del Litoral.

LEGUIZAMON PONDAL, GONZALO y ALBERTO GeLly CANTIlo (1923). Viracocha. Dibujos decorativos americanos. Buenos Aires: Comisión Nacional de Bellas Artes.

LEHMANN-NITSCHE, ROBERTO (1927). «El revestimiento con ocre rojo de tumbas prehistóricas y su significado». Revista del Museo de La Plata, tomo xxx (tercera serie, tomo vi), I45-I59. (1928, abril). «Coricancha. El Templo del Sol en el Cuzco y las imágenes de su altar mayor». Revista del Museo de La Plata XxxI, I-260.

LÉvi-STRAuss, dina (1937). «Société d’ethnographie et de folklore de São Paulo (Brésil)». Journal de la Société des Américanistes 2, Tomo 29, 429-431.

Liernur, francisco (200I). Arquitectura del Siglo XX en la Argentina. La construcción de la modernidad. Buenos Aires: Fondo Nacional de las Artes. lispector, clarice (1988). Silencio. Barcelona: Grijalbo. Traducción de Cristina Peri-Rossi. NOel, Martín s. (1916). «Arquitectura colonial». Plus Ultra I, s/p. onelli, Clemente (1916a). Alfombras. Tapices i tejidos criollos. Buenos Aires: Kraft. (1916b). «Tejidos criollos e indígenas». Revista de Arquitectura 7, s/p.

PATERnOsto, CÉSAR (1989). Piedra abstracta: la escultura inca, una visión contemporánea. Buenos Aires: Fondo de Cultura Económica. (1996). The Stone and the Thread: Andean Roots of Abstract Art. Austin: University of Texas Press. (200I). Abstracción: el paradigma amerindio. Valencia: IVAM. ROJAS, RICARDO (19I5). «Artes decorativas americanas». Revista de Arquitectura 4, a.I. (1930). Silabario de la Decoración Americana. Buenos Aires: Librería «La Facultad». SARLO, BeATRIz (1992). La imaginación técnica. Sueños modernos de la cultura argentina. Buenos Aires: Nueva Visión. 
SCOCCO, GRACIELA (2005-2006). "Arte textil tradicional: valoración, preservación y recuperación». Avances 9, 193-196.

SмIth, T'AI (20I4). Bauhaus Weaving Theory: From Feminine Craft to Mode of Design. Minneapolis: University of Minnesota Press.

spielmann, ellen (2003). Das Verschwinden Dina Lévi-Strauss' und der Transvestismus Mário de Andrades: Genealogische Rätsel in der Geschichte der Sozial- und Humanwissenschaften im modernen Brasilien (La desaparición de Dina Lévi-Strauss y el travestismo de Mário de Andrade: enigmas genealógicos en la historia de las ciencias sociales y humanas del Brasil moderno). BerlÍn: Wissenschaftlicher Verlag.

TORRES GARCía, JOAQUín (I965). La recuperación del objeto. Vol. 75/76. Montevideo: Biblioteca Artigas.

(1939). Metafisica de la prehistoria indoamericana. Montevideo: Publicaciones de la Asociación de Arte Constructivo.

\section{Copyright de las imágenes citadas en el texto}

FIg. 4 Extraída del libro corona, Salvador Macías - Josef Albers en México (I935-1976). Aproximaciones a la arquitectura mexicana. Barcelona: ETSAB-UPC, 2008.

FIgs. 5, 6, 7- (C) 2016 The Josef and Anni Albers Foundation / Artists Rights Society (ars), New York.

FIG. 8 Mário de Andrade - «Roupas freudianas/Fortaleza, 5- VII-27/Fotografiarefoulenta/ Refoulement/Sol 1 diaf. 1». Acervo do Instituto de Estudos Brasileiros da Universidade de São Paulo.

FIGs. 9, IO $\odot 2017$ The Josef and Anni Albers Foundation.

FIG. I3 (C) Artists Rights Society (ARs), New York / aDagp, Paris / Estate of Marcel Duchamp Update July 17, 20I2: (C) 2012 Artists Rights Society (ARS), New York / ADAgP, París / Succession Marcel Duchamp. 